PPPL-3458

PPPL-3458

UC-70

Visual Tritium Imaging Of In-Vessel Surfaces

by

C. A. Gentile, S. J. Zweben, C. H. Skinner, K. M. Young, S. W. Langish, M. F. Nishi, W. M. Shu, J. Parker, and K. Isobe

June 2000

$\int D \sqrt{D} \sqrt{5} \int \sqrt{\zeta} \int \begin{aligned} & \text { PAINCETON } \\ & \text { PLABMA PHYSICS } \\ & \text { LABOAATOAY }\end{aligned}$

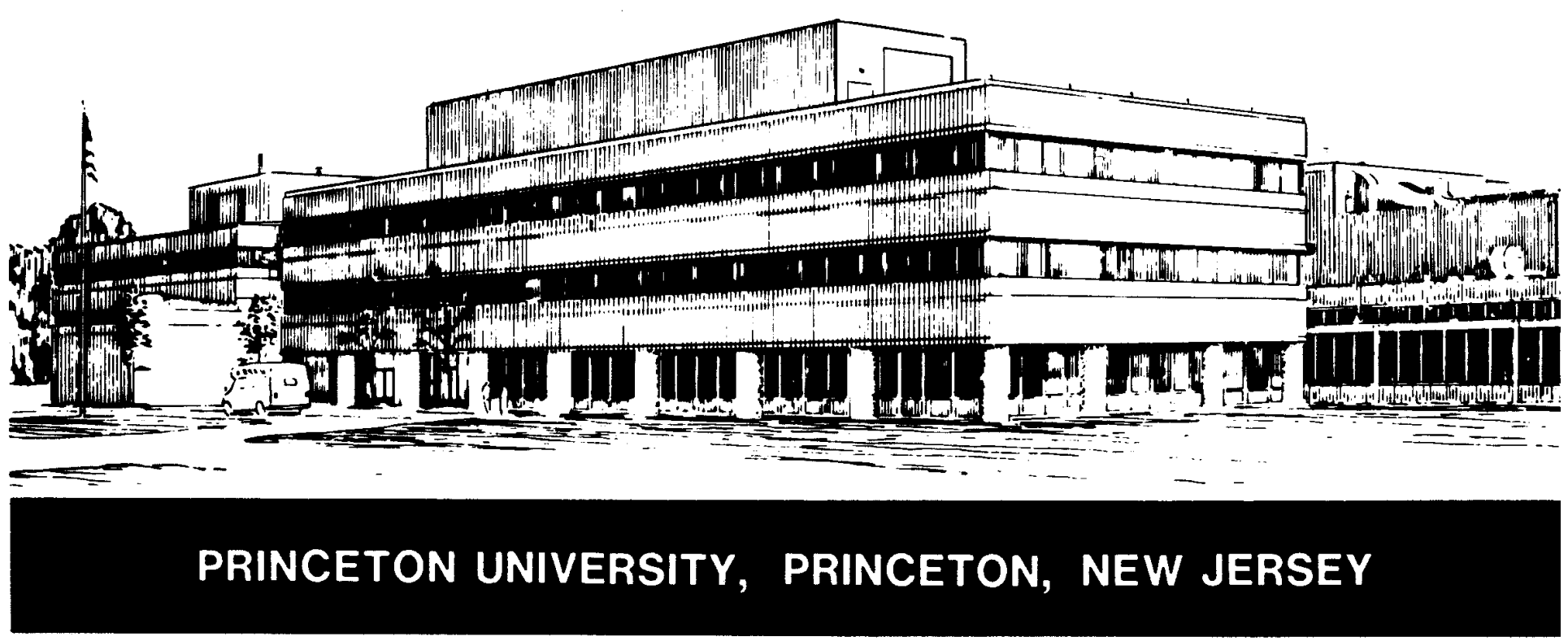




\section{PPPL Reports Disclaimer}

This report was prepared as an account of work sponsored by an agency of the United States Government. Neither the United States Government nor any agency thereof, nor any of their employees, makes any warranty, express or implied, or assumes any legal liability or responsibility for the accuracy, completeness, or usefulness of any information, apparatus, product, or process disclosed, or represents that its use would not infringe privately owned rights. Reference herein to any specific commercial product, process, or service by trade name, trademark, manufacturer, or otherwise, does not necessarily constitute or imply its endorsement, recommendation, or favoring by the United States Government or any agency thereof. The views and opinions of authors expressed herein do not necessarily state or reflect those of the United States Government or any agency thereof.

\section{Availability}

This report is posted on the U.S. Department of Energy's Princeton Plasma Physics Laboratory Publications and Reports web site in Calendar Year 2000. The home page for PPPL Reports and Publications is: http://www.pppl.gov/pub_report/

DOE and DOE Contractors can obtain copies of this report from:

U.S. Department of Energy

Office of Scientific and Technical Information

DOE Technical Information Services (DTIS)

P.O. Box 62

Oak Ridge, TN 37831

Telephone: (865) 576-8401

Fax: (865) 576-5728

Email: reports@adonis.osti.gov

This report is available to the general public from:

National Technical Information Service

U.S. Department of Commerce

5285 Port Royal Road

Springfield, VA 22161

Telephone: $1-800-553-6847$ or

(703) $605-6000$

Fax: (703) 321-8547

Internet: http://www.ntis.gov/ordering.htm 


\title{
Visual Tritium Imaging Of In-Vessel Surfaces
}

\author{
C. A. Gentile, S. J. Zweben, C. H. Skinner, K. M. Young, S. W. Langish, M. F. Nishi ${ }^{\mathrm{a}}$, W. M. \\ $\mathrm{Shu}^{\mathrm{a}}$, J. Parker, K. Isobe ${ }^{\mathrm{a}}$ \\ Princeton Plasma Physics Laboratory, Princeton University, Princeton, New Jersey, 08543 USA \\ ${ }^{a}$ Japan Atomic Energy Research Institute, \\ Tritium Engineering Laboratory, Tokai, Ibaraki 319-1195, Japan
}

\begin{abstract}
:
A imaging detector has been developed for the purpose of providing a non-destructive, real time method of determining tritium concentrations on the surface of internal TFTR vacuum vessel components. The detector employs a green phosphor screen (P31, zinc sulfide: copper) with a wave length peak of $530 \mathrm{~nm}$, a charge-coupled device (CCD) camera linked to a computer, and a detection chamber for inserting components recovered from the vacuum vessel. This detector is capable of determining tritium concentrations on the surfaces. The detector provides a method of imaging tritium deposition on the surfaces in a fairly rapid fashion.
\end{abstract}

Keywords: tritium retention, tritium co-deposition, tritium and tritide

\section{Introduction}

There is a need within the fusion energy community to better understand the physics associated with tritium deposition on internal vessel components. Future fusion energy machines will require relatively large quantities of tritium to operate. Therefore it is in the best interest of future fusion devices to accurately characterize tritium surface hold up in the vacuum vessel and, to maintain deposited and co-deposited tritium to a minimum.

The employment of tritium as a component of TFTR fusion fuel commenced during 1993 and continued on through 1997. During this time the TFTR tritium systems processed $\sim 1$ Mega Curie of tritium, of which $\sim 50,000 \mathrm{Ci}$ of tritium was supplied to the vacuum vessel through Neutral Beam Injection or by direct vessel gas injection [1]. At the completion of the TFTR D-T operational phase in April of 1997 the vacuum vessel was subject to a regimen of tritium cleanup operations which included vessel bake-out, deuterium Glow Discharge Cleaning, Helium / Oxygen Glow Discharge Cleaning, Pulse Discharge Cleaning, and moist air purges. At the end of this process it was estimated that $\sim 1$ gram of tritium still remained tenaciously bound to the surfaces inside the TFTR vacuum vessel [2].

Commencing in 1998, a collaboration was developed between PPPL and members of the JAERI Tritium Engineering Staff to investigate the co-deposition of tritium on the internal surfaces of the TFTR vacuum vessel [3]. In support of the PPPL / JAERI collaboration various tritium-assaying techniques were deployed to accurately determine the deposition characteristics associated with the tritium remaining on the surfaces of vacuum vessel components in the codeposited layer, both on carbon and stainless steel surfaces [4].

Several methods for determining tritium activity on surfaces have been developed. These include the deployment of open wall ion chambers, TLD's, smear surveys, and pin diodes [5,6 ]. The major advantages of the tritium imaging system described here compared to non-imaging techniques are that (a) the tritium imaging system used is non-destructive, as the surface of the 
item being imaged is not disturbed, (b) this imagining method provides a real time assaying technique, and (c) it is fast and relatively inexpensive $[7,8,9]$.

The major components of the detector are a P31 zinc sulfide: copper (green) phosphor plate, which emits a wavelength of $530 \mathrm{~nm}$ [10] and a long-time-integrating CCD camera. For ex-vessel detection the tritiated surface to be assayed is enclosed in a polycarbonate chamber with the phosphor plate maintained at a pre-determined distance above (never touching) the surface to be imaged. The polycarbonate chamber is placed in a light tight observation enclosure where an internally cooled CCD camera is positioned to capture photons emitted from the surface of the P31 phosphor plate, the result of tritium beta particles interacting with the phosphor coated onto the plate.

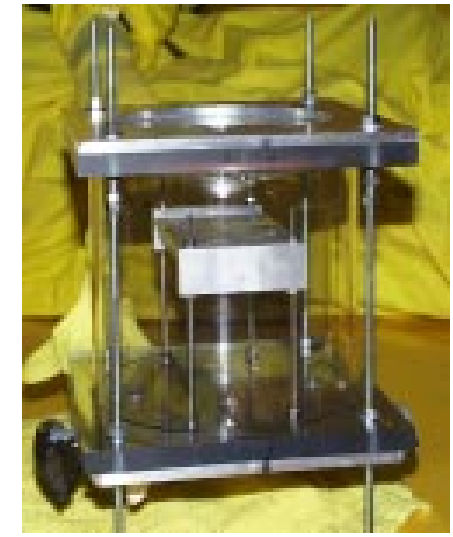

Figure 1. Polycarbonate Imaging Chamber

The polycarbonate imaging chamber incorporates an internal adjustable platform for positioning components of various physical dimensions to a pre determined distance under the fixed phosphor coated plate. Typically a distance of $1 \mathrm{~mm}$ between the surface to be measured and the phosphor plate is used. The chamber is capable of being pumped down to subatmospheric presuure or backfilled with lighter gases.

\section{Configuration}

Two configurations have been developed employing the tritium imaging system. The first is used for imaging tritiated surface components which have been removed from the TFTR vacuum vessel. In this ex-vessel configuration tritiated components are placed in a polycarbonate imaging chamber. The chamber can be evacuated and backfilled with various gases (typically helium), or pumped down to sub-atmospheric pressure to provide an environment where more beta particles from the surface of the tritiated material interact with the phosphor imaging plate. Tritium beta particles decay with an average energy of $5.6 \mathrm{KeV}$ and have a range in air of $\sim 4 \mathrm{~mm}-6 \mathrm{~mm}$. The range of the tritium beta particles at subatmospheric pressure or in lighter gases $(\mathrm{He})$ can be increased causing more beta particles to strike the phosphor plate.

For instances where in-situ imaging is desired the P31 phosphor plate is fixed to the end of a coherent fiber optic bundle with an appropriate lens. In this configuration the P31 phosphor plate is positioned $1 \mathrm{~mm}$ above an area (surface) of interest. In this configuration a soft collar (light seal) is jacketed around the phosphor coated plate and lens. When the area to be imaged is determined, the foam collar is positioned in a fashion, which reduces the background from visible light that may be present in the environment. The coherent fiber optic bundle transmits 
photons (generated by the interaction of tritium beta particles on the phosphor plate) to the CCD camera where the image is recorded.

Employing either of these configurations provides versatility in various measuring environments. Another advantage of surface tritium detection employing imaging is that mixed (gamma) radiation environments do not effect the imaging head (phosphor plate). In addition the system in (both) the ex-vessel configuration and in-situ configuration provides reliable measurements at sub atmospheric and atmospheric pressures with a variety of background gases.

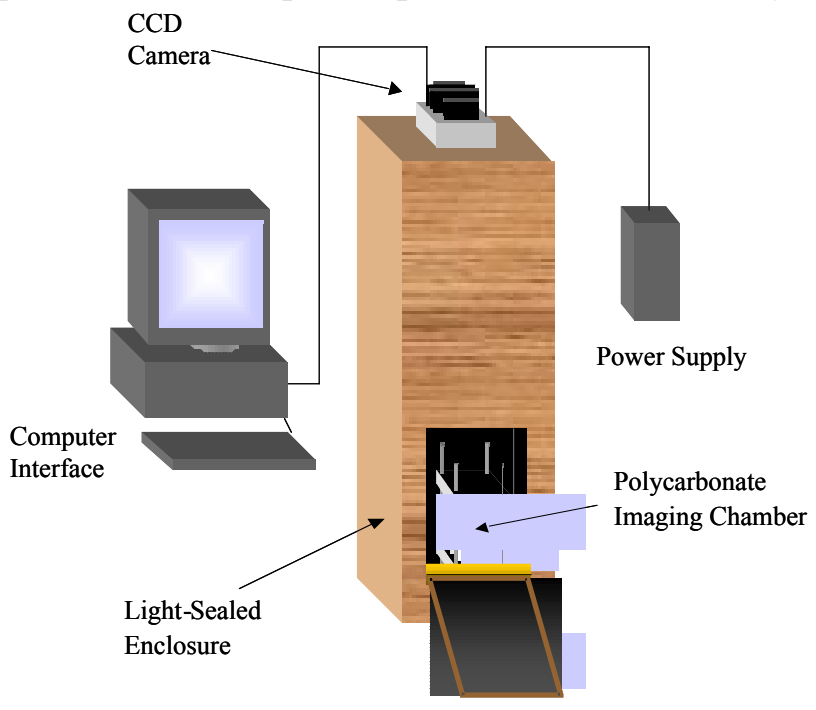

Figure 2. Ex-Vessel Tritium Imaging System Configuration

In this configuration the surface to be imaged is contained within a polycarbonate imaging chamber. Internal chamber conditions are varied to optomize the effect of the tritium beta particles interacting with the phosphor imaging plate. The phosphor plate is fixed at a predetermined position above the surface to be imaged, the same distance used during calibration, typically $1 \mathrm{~mm}$ above the surface of the tritiated material. The polycarbonate imaging chamber is placed in a light tight observation enclosure where light generated from the phosphor plate are collected onto a CCD camera and downloaded to a PC.

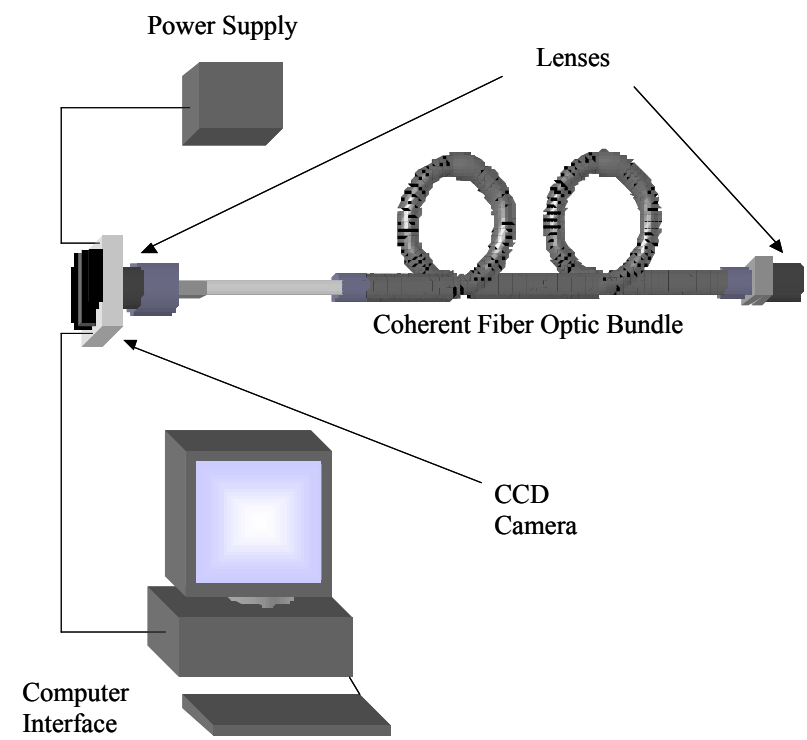

Figure 3. In-Situ Tritium Imaging System Configuration 
In this imagining configuration a coherent fiber optic bundle is employed for imaging tritiated surfaces in-situ. In this case a surface (bumper limiter tile in the vacuum vessel) can be scanned By hovering the head of the detector at a fixed distance above the surface. A light shield is employed to mitigate the effects of background light.

\section{System Calibration}

The system is calibrated by imaging known tritium standards of various concentrations and sizes under the same atmospheric pressure conditions and gas compositions as the tritium samples to be evaluated. Commercially available electroplated tritium standards are employed which can be fabricated in a variety of sizes, which can simulate many of the surface geometries of materials to be imaged. Typically it is best to use tritium standards that closely approximate the level of tritium on the surface of the item to be imaged. In the case of the TFTR D-T tiles tritium imagining calibration standards with a tritium activity in the hundreds of $\mathrm{uCi} / \mathrm{cm} 2$ range were employed to calibrate the system.

During calibration, the visible light intensity is recorded by a Roper Scientific Sensys model KAF1400- G2 CCD camera with wavelength sensitivity of $400-1100 \mathrm{~nm}$. Light from the interaction of the phosphor plate with a typical tritium calibration standard is integrated for a period of 100 seconds with the camera shutter open. The image of the phosphor plate intensity is recorded by the CCD camera and stored in the calibration file of the PC.

\section{Imagining}

The response of a P31 phosphor plate was calibrated using an electroplated tritium standard in atmospheric pressure at a distance of $1 \mathrm{~mm}$. The same phosphor plate was then fixed in position within the polycarbonate chamber $1 \mathrm{~mm}$ above TFTR D-T tile I-C-13 at atmospheric pressure. The polycarbonate chamber was placed in a light tight enclosure where photons generated by the interaction of tritium beta particles from the surface of the tile interacting with the phosphor coated onto the plate were collected by a CCD camera and compared to calibration data stored in the PC. The tile was then measured employing an open wall ion chamber which was placed on the surface of the tile and gave measurements within $20 \%$ on tile surface areas employing the imagining technique.

One major limiting factor affecting surface tritium detectors (open wall ion chambers, pin diodes, TLD's) is that the devices come into physical contact with the tritiated surfaces to be measured, are susceptible to cross contamination, and in some instances can change the conditions of fragile surfaces being measured. Tritium imaging employing the techniques described in this paper does not physically interact with the surface being measured and is therefore non-destructive and non invasive in determining surface tritium activity. 


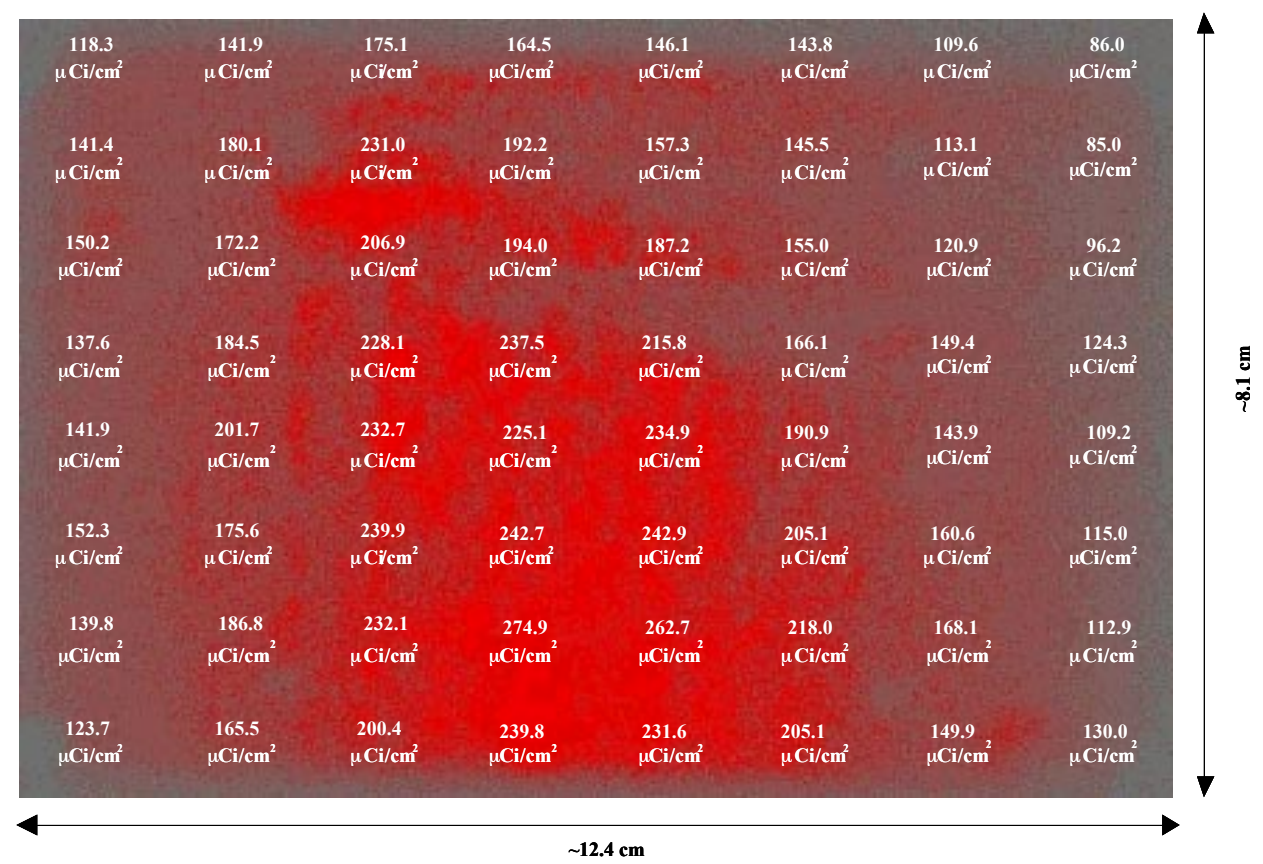

Total Surface Activity $=17564 \mu \mathrm{Ci}$

Mean Surface Activity $=175 \mu \mathrm{Ci} / \mathrm{cm}^{2}$

Figure 4. Surface Tritium Activity for TFTR D-T Tile \#I-C-13

In-situ measurements of in-vessel components are planned for the summer of 2000 during the next planned TFTR vacuum vessel entry. To date tritium standards have been imaged employing the in-situ configuration with good success. An engineered off-set is being designed to ensure that the phosphor imagining plate and lens is maintained at the (calibrated) fixed distance above the surface to be imaged.

\section{Conclusion}

The use of a tritium imaging system provides a non-destructive examination (no part of the surface to be measured is physically impacted by the detector) technique for measuring tritium surface contamination under a wide range of environmental conditions. The system is relatively inexpensive, and provides quantitative data fairly quick. The system can be employed for either ex-vessel or in-situ tritium imaging measurements. Such a detector provides a tool which can be employed in vacuum vessels to scan wall surfaces for tritium deposition, and determine tritium "hide-out" locations where tritium build up due to co-depositing may be increased due to wall geometry or plasma operating conditions.

\section{Acknowledgements}

The authors would like to acknowledge the contributions of Lloyd Ciebiera, William Walker, and Denis Shaltis for their craftsmanship in the fabrication of the tritium imaging components. Dr. Thomas Venhaus from Sandia National Laboratory who consulted and participated with the PPPL Tritium Staff in collecting tritium surface measurements from TFTR D-T tiles.

Funding for the development of the Visual Tritium Imaging System was provided by JAERI through the Annex IV to the JAERI/DOE Implementing Arrangement on Cooperation in Fusion Research and Development, and by USDOE Contract numbers DE-AC02-76CH03073 and DE-AC05-960R22464. 


\section{References}

[1] C.A. Gentile, M. Kalish, E. Amerescu, et al." The Operation of the TFTR Tritium System" IEEE/NPSS Symposium Fusion Engineering, Journal 97CB36131. Piscataway, N.J. (1997) $283-285$.

[2] A. Nagy, E. Amerescu,, W. Blanchard, et al. "Tritium Recovery from the TFTR Vessel" $17^{\text {th }}$ IEEE/NPSS Symposium Fusion Engineering, Journal 97CB36131. Piscataway, N.J. (1997)

$317-320$.

[3] C.H. Skinner, C.A.Gentile, K.M. Young, " Observations of Flaking of Co-deposited layers in TFTR" $18^{\text {th }}$ IEEE/NPSS Symposium on Fusion Engineering, Journal 0-7803-5829-5. (1999) 89 - 92.

[4] C.H. Skinner, C.A. Gentile, et al. These PSI Proceedings.

[5] C.A. Gentile, C.H. Skinner, K.M. Young, et al. "In-situ tritium Measurements of The Tokamak Fusion Test Reactor Bumper Limiter Tiles Post D-T operations" $5^{\text {th }}$ International Symposium on Fusion Nuclear Technology (1999).

[6] W.R. Wampler, B.L. Doyle, " Low-energy beta spectroscopy Using pin diodes to monitor tritium surface contamination" Nuclear Instruments and Methods in Physics research A 339. (1994) $473-480$.

[7] I. Youle, A.A. Haasz, "Profiling with Tritium Imagining", Journal of Nuclear Materials 248. (1997) 64 - 71.

[8] C.A. Gentile, S.J. Zweben, C.H. Skinner, et al. "A Visual Detection System for Determining Tritium Surface Deposition Employing Phosphor Coated Materials", $18^{\text {th }}$ IEEE/NPSS Symposium on Fusion Engineering, Journal 0-7803-5829-5. Piscataway N.J.. (1999) 319 - 320.

[9] S.J. Zweben, C.A. Gentile, D. Mueller, et al, "In-vessel tritium measurements using beta decay in the Tokamak Fusion Test Reactor", Review of Scientific Instruments 70. (1996) $1119-1122$.

[10] Phosphor Resource Manual for Industrial and Military Cathode Ray Tubes, Section 3 Standard Phosphors. 
The Princeton Plasma Physics Laboratory is operated by Princeton University under contract with the U.S. Department of Energy.

\author{
Information Services \\ Princeton Plasma Physics Laboratory \\ P.O. Box 451 \\ Princeton, NJ 08543
}

Phone: 609-243-2750

Fax: 609-243-2751

e-mail: pppl_info@pppl.gov

Internet Address: http://www.pppl.gov 